\title{
REGULARARTICLE
}

\section{INSECTICIDAL DETERRENCE OF WILD SPIKENARD (HYPTIS SUAVEOLENS L. POIT) ON ADULT MORTALITY AND FEMALE OVIPOSITION OF GROUNDNUT BRUCHID, CARYEDON SERRATUS OLIVIER ON STORED GROUNDNUT SEEDS AND TAMARIND PODS}

\author{
C. S. OAYA ${ }^{*}$, A. M. MALGWI², I. UMAR ${ }^{2}$, A. MOHAMMED3 \\ ${ }^{1}$ Department of Agricultural Technology, Adamawa State College of Agriculture, P. M. B.2088, Ganye, Adamawa State-Nigeria \\ ${ }^{2}$ Department of Crop Protection, School of Agriculture and Agricultural Technology, Modibbo Adama University of Technology, \\ P. M. B. 2076 Yola, Adamawa State, Nigeria
}

3Department of Crop Production and Protection Federal University Dutsin-ma, Katsina State

\begin{abstract}
An investigation was conducted to estimate the insecticidal deterrence of wild Spikenard (Hyptis suaveolens L. Poit) on adult mortality and female oviposition of groundnut bruchid, Caryedon serratus Olivier on stored groundnut seeds and tamarind pods. Data were taken on mean percentage mortality and mean number of eggs laid (female oviposition). The highest mean percentage mortality for both stored produces were reported in actellic dust and 12.0og levels of $H$. suaveolens whole powders (93.50; 91.75 and 92.25 ; 91.25) while the least were obtained in the controls $(4.75 ; 3.25)$. Moreover, 12.00 g levels of $H$. suaveolens whole powder and actellic dust recorded the least mean number of eggs laid (female oviposition) (18.00; 17.00 and 19.25; 18.00) while the highest was reported in the controls $(318.25 ; 305.50)$ respectively. There was no significant difference between the effects of rates of synthetic insecticides and $12.00 \mathrm{~g}$ level of $H$. suaveolens whole powder in all the parameters measured.
\end{abstract}

Keywords: Hyptis, Mortality, Oviposition, Groundnut, Tamarind, Bruchid

\section{INTRODUCTION}

Groundnut (Arachis hypogeae Linn) is one among the important cultivated legume of Fabaceae family [1]. It was originated from South America (Brazil) from where introduced in Nigeria $[2,3]$. Groundnut is widely cultivated in African countries [4, 5]. Tamarind (Tamarindus indica L.) is a cultivated tropical tree, since historical times $[6,7]$. The fruit and pulp are widely used in all parts of world for edible as well as industrial purposes [6]. In Nigeria, the products are mainly utilized in food industry $[8,9]$. The insect attack is a major threat for the cultivation and also post-harvest storage and processing of these plants. The beetle, Caryedon serratus Olivier (Coleoptera: Bruchidae) is the only insect species known to infest kernels and intact pods and is thus potentially the most important insect pest of stored groundnut and tamarind [10] and [9].

There are many control measures in common but most of them are not so efficient and effective control of the insect pests [11]. Some good practices are store hygiene, physical control, biological control, use of resistant crop varieties, cultural control methods and the use of inert materials. And the control of this beetle by chemical agents is the most effective method [12]; [13] and [14] but it has tremendous adverse effect to man, the livestock and the environment [15] and [16]. Therefore, a curious search for natural-product based agrochemicals that are biodegradable, eco-friendly, sustainable and safe to humans and the environment has intensified [17].

Hyptis suaveolens (L.) Poit, a potential anti-feedant plant product belongs to the family laminaceae [18]. Ethnobotanical studies conducted in Kenya on $H$. suaveolens showed that, the plant can repel mosquitoes effectively when burned overnight in rooms [19] and [20] also in his phytochemical and Ethnobotanical database refers to the plant as insect repellant. H. suaveolens is used for some Ethnobotanical applications in rural communities [21-23] and [24] and the plant is readily available close to villages, along roadsides, on farm steads etc [25]. It has been established that, $H$. suaveolens Poit contain some compounds that can control insects and nematodes [26] and [27].

Received 18 November 2017; Accepted 29 December 2017

*Corresponding Author

C. S. Oaya

Department of Agricultural Technology, Adamawa State College of Agriculture, P. M. B.2088, Ganye, Adamawa State-Nigeria

Email: oaya1010@yahoo.com

(T) This article is open access and licensed under the terms of the Creative Commons Attribution License (http://creativecommons.org/licenses/by/4.o/) which permits unrestricted, use, distribution and reproduction in any medium, or format for any purpose, even commercially provided the work is properly cited. Attribution - You must give appropriate credit, provide a link to the license, and indicate if changes were made. 
This work considered not only the use of leaves in powdered form but the whole Hiptis plant (leaves, seeds, stems and roots) ground into powder form. This knowledge was also instrumental in evaluating the effect of $H$. suaveolens L. Poit whole powder on the survival and reproductive potential of $C$. serratus Olivier on stored shelled groundnut seeds and tamarind whole pods, in the search for alternative control method instead of the use of expensive, toxic, harmful and imported synthetic insecticides.

\section{MATERIALS AND METHODS}

The test for insecticidal potentials of $H$. suaveolens (L.) Poit whole powder on stored shelled groundnut seeds and tamarind whole pods for the control of the groundnut bruchid, $C$. serratus Olivier were carried out in the Laboratory of the Department of Agricultural Technology, Adamawa State College of Agriculture, Ganye. The College is located at Gangwokki Village, Ganye Local Government Area within longitude $8{ }^{\circ} 16^{\prime \prime}$ North and latitude $12{ }^{\circ}$ East of the equator in the Northern Guinea Savannah agroecological zone of Nigeria [28].

\section{Preparation of groundnut seeds and tamarind whole (fruits and seeds)}

The shelled groundnut seeds and tamarind whole pods (fruits and seeds) used for the experiment were obtained from the local farmers at harvest around Ganye area. Local variety of shelled groundnut seeds called 'Kampalla' were used for the experiments while edable tamarind whole pods were used. The stored products were sorted out for infested and damaged ones and sealed in an air-tight polyethylene bag. The stored products were thereafter spread on the Laboratory bench or table for three (3) days to reduce the moisture content to recommended storage percentage of 12 .

\section{Culture and maintenance of test insects for laboratory test}

The adults $C$. serratus Olivier were collected from infested seeds of shelled groundnut and tamarind whole pods (fruits and seeds). The infested seeds and pods were maintained in the Laboratory in a clean uninfested Kliner jar at an ambient temperature of $35{ }^{\circ} \mathrm{C}$ and relative humidity of $70 \%$. The Kliner jar was covered with muslin cloth held tightly in place for adequate aeration of the culture and precluded entry or exit of insects. New generations of bruchids were obtained from this stock culture which also provided the source of test insects that was used for the Laboratory test as the cycle is repeated from one generation to the other.

\section{Collection and preparation of plant material, wild spikenard (H. susveolens (L.) Poit)}

The plant material used was the Wild Spikenard $(H$. suaveolens (L.) Poit) and it belongs to the family laminaceae. The plant material is readily available in Nigeria. It was collected from the vicinity of the main campus of Adamawa State College of Agriculture, Ganye, Adamawa State-Nigeria. The whole plant (leaves, seeds, bark, and flowers) was shade dried until all the water molecules evaporated and the plant organs well dried for grinding. The dried whole plant was mechanically powdered and sheaved using mesh and stored in an airtight container with proper labeling which was later used for further phytochemical analysis or qualitative test for the identification of various plant constituent and
Laboratory test for insecticidal potentials of the whole powder.

\section{Experimental design}

Completely Randomized Design was used for the Laboratory test for insecticidal potentials of Wild Spikenard, $H$. suaveolens L. Poit whole powder. There were six (6) levels of the plant material whole powder, Wild Spikenard (H. suaveolens) (2.00g, 4.0og, 6.0og, 8.0og, 10.00g, 12.00g), two rates of synthetic insecticide, actellic dust (2.00g and 4.00g) and a control treatment (o.oog) making a total of nine (9) treatments for each stored product (18 in total) which were replicated four (4) times giving a total of seventy two (72) Laboratory experimental units.

Test for insecticidal potentials of wild spikenard (H. suaveolens L. Poit) whole powder

Ten (10) paired freshly emerged adults of the groundnut bruchid, C. serratus Olivier [Coleoptera: Bruchidae] were introduced into $500 \mathrm{mls}$ storage containers already containing 3oograms of disinfested 'Kampalla' shelled groundnut seeds and tamarind whole pods that were treated with different levels of the plant material, $H$. suaveolens $\mathrm{L}$. Poit whole powder, 2.00g, 4.00g, 6.00g, 8.00g, 10.00g, $12.00 \mathrm{~g}$, two rates of the synthetic insecticide, actellic dust (2.0og and 4.0og) and the control (0.00g). The initial weight of the stored products was taken and the moisture content of the stored products was $12 \%$. The groundnut seeds and the tamarind whole (fruits and seeds) were properly coated with the plant material whole powder and thoroughly shaken to ensure uniform spread of the powder. The storage containers were covered with muslin cloth to prevent suffocation and entry or exit of the test insects.

The stored products already treated with six (6) levels of $H$. suaveolens L. Poit whole powder, the two rates of synthetic insecticide, actellic dust and the untreated control were replicated four (4) times making a total of seventy two (72) experimental units for the two stored products arranged in a Completely Randomized Design setting in the Laboratory. The experimental set up was left undisturbed for 1, 2 and 3 mo respectively to evaluate the insecticidal potentials of $H$. suaveolens L. Poit whole powder for the control of groundnut bruchids, C. serratus Olivier on stored shelled groundnut seeds and tamarind whole pods.

\section{Data collection}

The data collected include the following:

\section{Mean percentage mortality}

Mean percentage mortality was determined using the formula as reported by [29].

$$
=\frac{\text { Number of dead adult bruchids }}{\text { Total number of bruchids (alive and dead) }} \times 100
$$

\section{Mean number of eggs laid}

The mean number of eggs laid in each of the storage container was counted manually at 1, 2 and 3 mo of storage respectively.

\section{Statistical analysis}

Data collected were subjected to the analysis of variance (ANOVA) appropriate to Completely Randomized Design 
according to [30]. The treatment means were separated using the Student Newman Keuls (SNK) at $\mathrm{P}<0.05$ level of probability.

\section{RESULTS}

The result of mean percentage mortality and number of eggs laid as influenced by interaction effects between levels of control measures and stored products stored is presented in table 1 . The result showed that, the highest mean percentage mortality for both stored products was reported in 4.00g rates of actellic dust (93.50 and 94.00) followed by 2.oog rates of actellic dust (92.25 and 92.75), 12.0og levels of $H$. suaveolens whole powder ( 91.25 and $89.75)$, 10.0og levels of $H$. suaveolens whole powder (83.50 and 81.50), 8.oog levels of $H$. suaveolens whole powder (72.75 and 69.75), 6.oog levels of $H$. suaveolens whole powder (62.50 and 61.75), 4.00g levels of $H$. suaveolens whole powder (54.50 and 46.75), 2.00g levels of $H$. suaveolens whole powder ( 36.50 and 34.50$)$ and the least was recorded in the controls $0.00 g$ ( 3.50 and 3.00) respectively. However, the result also showed that, there was no significant difference between the effect of $12.00 \mathrm{~g}$ levels of $H$. suaveolens whole powder and the two rates of the actellic dust on mean percentage mortality is shown in table 1.

The result of mean number of eggs laid as influenced by interaction effect of levels of control measures and stored products stored is also presented in table 1 . The result showed that, the controls, o.oog recorded the highest mean number of eggs laid stored from November-January (306.00 and 293.50) followed by $2.00 \mathrm{~g}$ levels of $H$. suaveolens whole powder (149.50 and 131.25), 4.0og levels of $H$. suaveolens whole powder (68.75 and 65.25), 6.00g levels of $H$. suaveolens whole powder (44.00 and 29.50), 8.00 levels of $H$. suaveolens whole powder (29.50 and 28.00), 10.0og levels of $H$. sualeolens whole powder (24.00 and 22.75), 12.00g levels of $H$. suaveolens whole powder (13.00 and 12.50), 2.00g rates of actellic dust (11.75 and 11.25) and the least was recorded in 4.0og levels of actellic dust (9.75 and 9.50). There was significant difference among the levels of control measures and between the stored products. However, there was no significant difference between the effects of 12.00 g levels of $H$. suaveolens whole powder and the two rates of actellic dust interms of number of eggs laid at $P \leq 0.05$ level of probability as reported in table 1 .

\section{DISCUSSION}

The results obtained showed that, there was no significant difference in mean percentage mortality between the effect of 2.00g and 4.00g rates of actellic dust and 12.00g level of plant material, H. suaveolens L. Poit whole powder on shelled groundnut seeds and tamarind whole pods for the control of bruchid, C. serratus Olivier in store. This apparently means that both synthetic insecticides (actellic dust) and 12.0og level of plant material, $H$. suaveolens $\mathrm{L}$. Poit whole powder recorded higher mean percentage mortality as shown by the results obtained. This observation suggested that both the synthetic insecticides and the plant material whole powder demonstrated to a large extent ovicidal deterrence and larvicidal activities that inactivated the bruchids by their cytotoxic, toxic and phytotoxic properties resulting in high mortality as shown by the results. This finding agrees with other workers like [12], [16] and [14] who reported that chemical insect pests control both in the field and in store appears to be the most effective method of control due to its quick action but it has tremendous adverse effects on man, the livestock and the environment as well. The study further shows that, $H$. suaveolens L. Poit whole plant powder is a potential antifeedant plant product that is effective, safe, biodegradable, eco-friendly and sustainable. This is in agreement with $[25-27,31]$ who reported that $H$. suaveolens L. Poit plant contain some chemical compounds such as tannins, alkaloids, aldehydes, phenols ketones etc that could be used to control both insects and nematodes.

The highest mean number of eggs laid was recorded in the controls as shown in the results obtained for both stored products. This high mean number of eggs laid was because the test insects were introduced into the storage container with the stored products with no protectants (control measures) to suppress oviposition or the egg laying ability of the bruchids.

This agrees with [32] and [33] who reported that, adult female $C$. serratus Olivier can lay more than 70 eggs under optimum favourable conditions. They also observed that, storing shelled groundnut seeds in particular without the application of any storage measure is a futile exercise since oviposition and larval development will not be distracted and as such more damage will be recorded.

Table 1: Mean percentage mortality and number of eggs laid as influenced by interaction effects of control measures and stored products

\begin{tabular}{|c|c|c|c|c|}
\hline Treatments & \multicolumn{2}{|c|}{ Mortality (\%) groundnut tamarind } & \multicolumn{2}{|c|}{ Number of eggs laid groundnut tamarind } \\
\hline O.oog & $3.50^{h}$ & $3.00^{g}$ & $306.00^{\mathrm{a}}$ & $293.50^{\mathrm{a}}$ \\
\hline $2.00 g$ & $36.50^{\mathrm{g}}$ & $34 \cdot 50^{\mathrm{h}}$ & $149 \cdot 5^{\mathrm{b}}$ & $131.25^{\mathrm{b}}$ \\
\hline $4.00 g$ & $54.50^{f}$ & $46.75^{\mathrm{g}}$ & $68.75^{\mathrm{c}}$ & $65.25^{\mathrm{c}}$ \\
\hline $6.00 \mathrm{~g}$ & $62.50^{\mathrm{e}}$ & $61.75^{\mathrm{f}}$ & $44.00^{\mathrm{d}}$ & $29.50^{\mathrm{d}}$ \\
\hline $8.00 g$ & $72.73^{\mathrm{d}}$ & $69.75^{\mathrm{e}}$ & $29.50^{\mathrm{e}}$ & $28.00^{\mathrm{e}}$ \\
\hline $10.00 \mathrm{~g}$ & $83.50^{c}$ & $81.50^{\mathrm{d}}$ & $24.00^{f}$ & $22.75^{\mathrm{f}}$ \\
\hline $12.00 \mathrm{~g}$ & $91.25^{\mathrm{b}}$ & $89.75^{c}$ & $13.00^{g}$ & $12.5^{\mathrm{g}}$ \\
\hline 2.oogActellic dust & $92.25^{\mathrm{b}}$ & $92.75^{\mathrm{b}}$ & $11.75^{\text {gh }}$ & $11.25^{\mathrm{g}}$ \\
\hline 4.oogActellic dust & $93.50^{\mathrm{a}}$ & $94.00^{\mathrm{a}}$ & $9.75^{\text {gh }}$ & $9 \cdot 5 \mathrm{O}^{\mathrm{h}}$ \\
\hline $\mathrm{P}<\mathrm{F}$ & 0.05 & 0.01 & 0.02 & 0.01 \\
\hline C. V & 0.90 & 0.80 & 2.00 & 0.80 \\
\hline S. E & 0.57 & 0.53 & 1.39 & 0.55 \\
\hline
\end{tabular}

Mean followed by the same letter (s) in the same column is not significantly different at $P \leq 0.05$ level of probability using the Student Newman-Keuls (SNK) method of mean separation 
The synthetic insecticides, actellic dust (2.oog and 4.oog) and 12.00 g level of plant material, $H$. suaveolens L. Poit whole powder recorded the lowest mean number of eggs laid respectively. This was because both actellic dust and levels of $H$. suaveolens whole powder had oviposition deterrence effect on the groundnut bruchids. The low number of eggs laid in stored products treated with varying levels of plant material whole powder especially 12.0og and 10.0og levels was because the plant material powder contained some inhibitory compounds like phenols, tannins, ketones, alkaloids, glycosides etc that inactivated the bruchids prior to oviposition and subsequently prevented egg and larval development. This is consistent with [34] and [16] who suggested that plant material powder could significantly reduce egg laying ability, larval development and also suppress adult emergence. Similarly, [31] reported that plant materials contain some toxic chemical constituents which inhibits and suppress oviposition and the observed results could be a direct consequences of reduction in egg production or inhibition of egg laying or both. Moreover, other levels of plant material whole powder also recorded slightly low mean number of eggs laid by the groundnut bruchid, $C$. serratus Olivier compared to the control as reported.

\section{CONCLUSION}

The application of the whole plant powder of $H$. suaveolens L. Poit to store shelled groundnut seeds and tamarind whole pods for the control of the bruchid, $C$. serratus Olivier was effective since the mean percentage mortality was high and the number of eggs laid (oviposition) was low at all levels of powder compared to the control. $H$. suaveolens L. Poit whole plant powder also competed favourably with the synthetic insecticides especially the $12.00 \mathrm{~g}$ and $10.00 \mathrm{~g}$ levels of the plant material whole powder.

\section{REFERENCES}

1. Beghnin, J. and Sewadah, M. (2003). The Impact of Groundnut Trade Liberalization. Tim Hill Publishing Company Limited India. Pp. 241-242.

2. Adeyemi, S. A. (1968). Storage Entomology; Proceedings of Agricultural Society of Nigeria. Vol. 34 .

3. Malgwi, A. M., Samaila, A. E., Yemisi, J. O. and Oaya, C. S. (2013). The Effect of Groundnut Sucking Bug (Rhyparochromus littoralis Dist.) on the Oil Content of Groundnut Kernels on Two Groundnut Cultivars in Northern Nigeria. Journal of Food Science and Quality Management, Volume 11, Pp. 70-75.

4. Ashely, J. (1993). Drought and Adaptation: In Dry Land Farming in Africa (Rowland, R. J. ed). Macmillan Education Ltd. London Pp. 10.

5. ICRISAT (International Crop Research Institute for Semi-arid Tropics) (2015). Farmer's Guide to Profitable Groundnut Production in Nigeria. Patancherum, 502324, Telengana, India. International Crops Research Institute for Semi-Arid Tropics. 36pp.

6. Dalton, H. J. (1991). Agriculture in the Tropics and sub-Tropics. Longman Group Ltd. London Pp. 19.

7. Hooker, J. D. (1991). The Flora of British India. Viol. II. L. Reeve and company Ltd. London. 25Pp.

8. Fosberg, F. R. (2005). Handbook of Flora of Ceylon. Washington, D. C. Smithsnian Institute. Pp. 25-27.

9. Oaya, C. S., Malgwi, A. M. and Samaila, A. E. (2012). Damage Potential and Loss Caused by the Groundnut Bruchid Caryedon serratus Olivier [Coleoptera:
Bruchidae] on Stored Groundnut and Tamarind in Yola. International Organization of Scientific Research, India. Journal of Agriculture and Veterinary Science, Volume 1, Issue 6, Pages 58-62.

10. Panday, G., Bhatt, P., Kanaujia, S., Kanaujia, K. R., Jyothi, K. N. and Prasuna, A. L. (2011). Studies on Elecrophysiology, Olfactometric Response and Chemical Analysis of Groundnut Extracts against the Groundnut Bruchid Caryedon serratus. Journal of Agricultural Technology, Volume 7, Pp. 1265-1273.

11. Adebowole, K. O. and Adedire, C. O. (2006). Chemical Composition and Insecticidal Properties of the Underutilized Jatropha curcas Seed Oil. African Journal of Biotechnology, Volume 5, Pp. 901-906.

12. Jackai, L. E. N. and Daoust, R. A. (1986). Insect Pest of Cowpea. Annals Rev. Entomology, 31:95-119.

13. Adedire, C. O. and Lajidire, L. (1999). Toxicity and Oviposition Deterancy of some Plant extracts on cowpea Storage Bruchid Calosobruchus maculatus Fab. Journal of Plants Diseases and Protection 106, 547-651.

14. Oaya, C. S., Kwaji, C. I. and Agwanda, G. A. (2011). Integrated Pest Management (IPM) for Callosobruchus maculatus Fab. on Stored Cowpea in Yola, Adamawa State. International Journal of Agriculture, 3, 51-55.

15. Makanjoula, W. A. (1989). Evaluation of Extracts of Neem (Azadirachta indica A. Juss) for the Control of Some Stored Products Pests. Journal of Stored Product Research, 25:23

16. Adedire, C. O. and Lajidire, L. (2000). Toxicity and Oviposition Deterancy of some Plant extracts on cowpea Storage Bruchid Calosobruchus maculatus Fab. Journal of Plants Diseases and Protection 106, 547-651.

17. Jadhau, K. B. and Jadhau, L. D. (2006). Use of Vegetable Oils, Plant Extracts and Synthetic Products as Protectants from Pulse Beetle, Callosobruchus maculatus in Stored Grain. Journal of Food Science Technology, 21:110-113.

18. Raja, N., Jeyasanker, A., Jeyakumar, V. S. and Ignicimuthu, S. (2005). Efficacy of Hyptis suaveolens against Lepidopteran Pests. Current Science, 88: 220222.

19. Abagli, A. Z. and Alvo, T. B. C. (2011). Essential Oil from Bush mint Hyptis suaveolens, is as Effective as DEET for Personal Protection against Mosquito Bites. The Open Entomology Journal, Volume 5, Pp.45-48

20. Duke, J. A. (2007). Duke's Phytochemical and Ethnobotanical and Databases (htt://www. ars-grin. gov/cgi-bin/duke/ethnobot.pl).

21. Koumauglo, H. K., Akpagana, K., Glitho, I. A., AddaeMensah, I., Maudachirou, M. and Garnean, F. (1995). La Cooperation Sud-Suddans Trois Pay d' Afrique naire: Benin, Togo, Ghana. Actes du Colloque de Chicoutimi Surla Valorisation de la Biomasse Vesetace Parless. Product Nature Quebec, 22-25 Aout, 1993, Pp. 97-103.

22. Kossou, K. D., Gbenounou, G., Ahanchede, A., Ahohouendo, B., Bauraima, Y. and Vanttuis, A. (2001). Indigenous Cowpea Production and Protection in Benin. Insect Science and its Application, $21: 123-125$.

23. Edeoga, H. O., Omasun, G. and Uche, L. C. (2006). Chemical Composition of Hyptis suaveolens and 
Ocimun gratissimun Hybrids from Nigeria. African Journal of Biotechnology, 5: 892-895.

24. Oaya, C. S., Malgwi, A. M. and Samaila, A. E. (2013). Insecticiadal Efficacy of African Rock fig. Leaf Powder (Ficus congensis Engl.) Against the Groundnut Bruchid (Caryedon serratus Olivier) on Stored Groundnut in Yola. Journal of Agriculture and Veterinary Science, volume 2, issue 1, Pp. 24-27.

25. Adda, C., Atachi, A., Hell, K. and Tamo, M. (2011). Potential Use of the Bushmint, Hyptis suaveolens for the Control of Infestation by the Pink Stalk Borer Sesamia calamistis on Maize in Southern Benin, West Africa. Journal of Insect Science, Volume 1, Article 33, Pp. 1-13.

26. Oyedunmade, E. E. A. (1998). Control of Nematode Pests of Cowpea with Mocap (Ethoprop), Leaf Residues of Neem (Azadirachta indica), Rattle Weed (Crotalaria retusa) and Nitta (Hyptis suaveolens). Centerpoint Science Edition, 8: 57-63.

27. Musa, A. K., Dike, M. C. and Onu, I. (2009). Evaluation of Nitta (Hyptis suaveolens Poit.) Seed and Leaf Extract and Seed Powder for the Control of Trogoderma granarium Everts (Coleoptera: Dermestidae) in Stored Groundnut. AmericanEurasian Journal of Agronomy, 2: 176-179.

28. Adebayo, A. A. (1999). Climate II In: Adebayo, A. A. and Tukur, A. L. (eds) 1999 Adamawa State in Maps. Pp. 23-25. Paraclete Publishers, Jimeta Yola.
29. Dick, K. M. (1987). Pest Management in Stored Groundnut. Chapman and Hall, London. Pp. 365.

30. Gomez, K. A. and Gomez A. A. (1984). Statistical Procedure for Agricultural Research. John Welley and Sons New York. Pp. 21-23.

31. Oaya, C. S. and Jada, M. Y. (2013). Efficacy of Wild Spikenard (Hyptis suaveolens (L.) Poit) Leaf Powder against the Cowpea Bruchid (Callosobruchus maculatus Fab.) [Coleoptera: Bruchidae] on Stored Cowpea. African Journal of Agricultural Research and Development, Volume 6, Number 3, 2013. Pages 41-46.

32. Lale, N. E. S. (2002). Stored Product Entomology and Acarology in Tropical Africa. Mole Publication Nigeria Ltd. Pp.5o-6o.

33. Malgwi, A. M. and Oaya, C. S. (2014). Towards Achieving an Integrated Pest Management for the Control of the Groundnut Bruchid (Caryedon serratus Olivier) on Stored Groundnut and Tamarind inYola, Nigeria. Global Journal of Biology, Agriculture and Health Sciences, Vol. 3:96-104.

34. Ofuya, T. I. (1990). Oviposition Deterrence and Ovicidal Properties of Some Plant Powders against Callosobruchus maculatus in Stored Cowpea (Vigna unguiculata) Seeds. Journal of Agricultural Science Cambridge 115:343-345. 